\title{
From Perceptions to Practice: Factors Affecting Recast
}

\author{
Sajjad Sepehrinia \\ M.A. in TEFL, University of Tehran, Tehran, Iran \\ E-mail: ssepehrinia@yahoo.com \\ Alireza Zarea \\ M.A. in TEFL, University of Tehran, Tehran, Iran \\ E-mail: alireza_zarea@hotmail.com \\ Majid Soltani Moghaddam \\ M.A. in TEFL, University of Tehran, Tehran, Iran \\ E-mail:mjd.slm@gmail.com \\ Morteza Nasiri \\ M.A. in TEFL, University of Tehran, Tehran, Iran \\ E-mail: mortezanasiri85@yahoo.com
}

Received: May 7, $2011 \quad$ Accepted: June 2, $2011 \quad$ doi:10.5539/ijel.v1n2p18

\begin{abstract}
This review study was motivated by a debate about the role of recast in L2 learning. Recast is the most frequent type of feedback but probably the least effective one. While some researchers have criticized it as inefficient, others have supported it as an unobtrusive type of feedback especially useful during interactive activities. This review of studies on recast helps pinpoint the factors contributing to the effectiveness of recast. In this regard, two factors were found to have a determining role; saliency and learners' proficiency level. Saliency concerns the noticeability of recast by learners. Different factors affect saliency including shortness of recast, added-stress on the erroneous part, number of corrections, and the focus of recast. On the other hand, the results of studies confirm the role of proficiency. In other words, proficient learners are more likely to notice their errors using recast even when it is insalient.
\end{abstract}

Keywords: Recast, Feedback, Saliency, Proficiency

\section{Introduction}

Recasts as one of the major types of corrective feedback have been under the spotlight in much recent SLA research. Nicholas et al. (2001) defined recasts as "the teachers' correct restatement of learners' incorrectly formed utterance" (p. 720). To put it simply, recasts reformulate a learner's utterance into correct utterance. This feedback type is believed to be conducive to L2 acquisition (e.g., Nassaji, 2009; Sheen, 2006). However, how and under what conditions the most can be obtained from this type of feedback and what characteristics of it work for or against its effectiveness are but a few_not yet conclusively answered - questions in need of further research. This review study is intended to shed some light on these questions and to pinpoint major factors contributing to efficiency of recasts in different instructional and experimental contexts.

There are two contrasting views on the effectiveness of recasts. As Ammar and Spada (2006) note, some researchers advocate recast as an effective corrective feedback (CF) technique because they are implicit, unobtrusive, and contingent on the learners' intended meaning (Doughty, 2001; Doughty and Varela, 1998; Leeman, 2003; Long, 1996; Oliver, 1995). On the contrary, some (Truscott, 1999; Truscott and Hsu, 2008) criticize it as ineffective, inefficient and useless.

Studies on recast are of two types: observational and experimental. In observational studies, researchers observe a classroom for a period of time and consider learners' errors and language teachers' correction practices accordingly. In these studies, researchers observe and report the effect of different types of feedback on learners' interlanguage development. In experimental studies, on the other hand, the effect of a specific treatment or variable related to feedback on learners' interlanguage development is considered. All the researchers that have conducted their studies using observation (Fanselow, 1977; Lyster, 1998b; Lyster and Ranta, 1997; Panova and Lyster, 2002; Sheen, 2004) have come to the conclusion that recast is the least effective in comparison with other types of feedback. However, the results of experimental studies show that recast can be as effective if learners' 
attention is drawn to the error using some techniques (Lowen and Philp, 2006; Nassaji, 2007; Panova and Lyster, 2002; Sheen, 2006; etc).

\section{Review of the Literature}

Lyster and Ranta (1997) defined recast as a type of feedback in which the teacher implicitly reformulates student's error or provides correction without directly indicating that the utterance was incorrect. The results of their study revealed a clear preference for recast and translation as implicit types of reformulative feedback leaving little opportunity for other types of feedback that encourage learner-generated repair. They attributed the low rates of learner uptake and immediate repair of error to the frequent use of recast. Lyster and Ranta argued that L2 learners might benefit more from retrieval and production processes than from only hearing target forms in the input. In other words, in order for input or feedback to turn into uptake, teachers should encourage learner-generated repair i.e. metalinguistic, elicitation, clarification request, and repetition rather than explicit correction or recast. The findings of Lyster and Ranta's study are in line with Corder's (1981) assertion that simple provision of correct form bars the way to the learners testing alternative hypotheses. Corder contends that making learners discover the right grammatical form on their own could often be more instructive.

\subsection{Observational Studies}

The results of Lyster and Ranta's (1997) study parallels findings obtained in other observational studies with child and adult language learners (Fanselow, 1977; Panova and Lyster, 2002; Sheen, 2004; etc). Panova and Lyster (2002), for example, conducted an observational study of patterns of error treatment in an adult ESL classroom. They examined the range and types of feedback used by the teacher and their relationship to learner uptake and immediate repair of errors. The results were consistent with the findings of Lyster and Ranta (1997) showing a clear preference for implicit types of reformulative feedback, i.e. recasts and translation. Panova and Lyster included 'translation' in the patterns of feedback classified by Lyster and Ranta (1997). According to them, 'translation' can be seen as a feedback move when it follows a learner's unsolicited uses of the L1. In essence, 'translation' is a type of recast. Both have the similar function of reformulating non-target learner utterances. There is, nevertheless, a difference between a recast (a response to an ill-formed utterance in the L2) and a translation (a response to a well-formed utterance in the L1). Recasts included $55 \%$ of the feedback moves and translations included $22 \%$ of the feedback provided accounting for the low level of uptake. Panova and Lyster discovered that recasts that reduce the learner's utterance and add stress to emphasize corrected error lead to a high rate of uptake and are more likely to be perceived by learners as corrective feedback. Surprisingly, only $23 \%$ of all feedback moves belonged to other types of feedback indicating that the teachers strongly preferred to use reformulative techniques, such as recasts and translation, rather than feedback types that prompt students to self-repair. As in Lyster and Ranta's (1997) study, although recast was found to be more dominant than other forms of feedback, the highest rates of learner uptake (100\%) occurred with clarification requests, elicitation, and repetition which involved some kind of self-generated repair. The rate of uptake was also high in metalinguistic feedback. However, because of the low rate of occurrence of these types of feedback, a firm conclusion cannot be drawn about their effectiveness.

Fanselow (1977) analyzed the corrective techniques of L1 teachers during oral activities in adult ESL classrooms. He found that feedback was confusing to learners in that they often received contradictory signals simultaneously with respect to the content and the form of their utterances. The most common type of feedback among the 16 types of verbal and nonverbal teacher reactions to learner errors was the teacher's provision of the target language form (i.e., recasts); as a result, opportunities for self-repair were minimal. Learners noticed the forms that they were pushed to self-repair more than forms that were implicitly provided by teachers. As Truscott $(1996$; 1999) also notes, insaliency of recasts creates difficulties for learners in recognizing the correction and they may even misunderstand the correction.

Sheen (2004) pointed out the importance of saliency of recast for its effectiveness. He examined four communicative classroom settings - French Immersion, Canada ESL, New Zealand ESL and Korean EFL using Lyster and Ranta's taxonomy of corrective feedback moves and learner uptake. Sheen investigated different types of feedback used in different contexts and the level of uptake following each feedback strategy and degree of effectiveness of different types of feedback. She found out that the extent to which recasts lead to learner uptake and repair may be greater in contexts that the focus of recasts is more salient and learners can easily detect and notice the existing gaps.

As the results of above-mentioned studies show, more than half of the feedback provided was in the form of recast, but the level of uptake for recast was at its lowest level in comparison with other forms of feedback that encouraged self-correction. And apparently the most important reason as to the ineffectiveness of recast is that learners have difficulty recognizing it as a form of corrective feedback. However, none of the studies discussed above focused specifically on the factors that might have led to the ineffectiveness of recast, though some (e.g. Panova and Lyster, 2002) parenthetically mentioned that adding stress and reducing the error makes it likely for learners to notice the recast. They observed and analyzed the patterns of feedback in language learning classrooms and reported what they observed. 


\subsection{Experimental Studies}

Although it seems that recast has not proved beneficial according to the findings of above-mentioned studies (Fanselow, 1977; Lyster and Ranta, 1997; Panova and Lyster, 1998; Sheen, 2004; etc.), some researchers (Ammar and Spada, 2006; Ellis and Sheen, 2006; Lyster, 1998b; Philp, 2003; Sheen, 2006) tried to delve deeply into the root of the problem and to investigate the effect of different facilitative or intervening factors affecting learners' perception and noticing of recast. They considered the effect of factors that affect learners' perception of recast. A brief look through these studies shows that in all the studies similar reasons have been pointed out as to the cause of inefficiency of recast. In other words, there are a number of factors that make recast insalient or ambiguous so that they might be taken for 'confirmation checks' or go unnoticed by the learners. The results of these studies reveal the effect of two factors on learners' success or failure in noticing feedback. One of the factors concerns the linguistic features of recasts and the other has to do with learners' proficiency level. Linguistic factors have to do with the length of recast (short or long), number of changes and the components of language, i.e. whether the focus of feedback or recast is on grammatical, lexical or phonological errors made by the learners.

Lyster (1998b), for instance, analyzed the patterns of feedback in Lyster and Ranta (1997) and the features of context and interaction that might have led to the low level of uptake for recasts. He noticed that teachers used non-corrective repetitions and recasts in the same way. In other words, recasts and non-corrective repetitions fulfilled the same function. After learners' erroneous utterances, the teacher recast the learners' error and also repeated their utterance to show approval of the content. Therefore, learners had difficulty distinguishing non-corrective repetition or confirmation check from recast.

In line with Lyster's (1998b) finding, one of the criticisms leveled against the use of corrective feedback especially recast is that language learners do not recognize when their teacher is providing feedback and even if they do, they do not modify their output. In other words, feedback and especially recast does not lead to any improvement in learners' interlanguage (Truscott, 1996; 1999). According to Lyster (1998b), language learners mistakenly take 'recast' for 'confirmation check'. It might be even that learners have not noticed recasts and pretend that they have. As Gass (2003) notes, learners' repair after recasts might be just a kind of mimicking (mere repetition of the correct form without analysis or revision) without really finding the gap between their interlanguage and the feedback provided in the form of recast.

In a more comprehensive experimental study, Ellis, Loewen and Erlam (2006) investigated the effect of metalinguistic (explicit) feedback and implicit feedback (recast) on learners' interlanguage development in classroom context. In this study, low-intermediate learners of English completed two communicative tasks during which they received feedback in the form of recasts or metalinguistic feedback. The results of this study confirmed a clear advantage for metalinguistic (explicit) feedback over recast. According to Ellis et al., "explicit feedback seems more likely to promote cognitive comparison that aids learning" (p. 364).

Ammar (2008) came to the same conclusion this time with prompts. In a quasi-experimental study, he compared the effect of prompts and recast on Francophone learners' acquisition of third person possessive determiners. Again, prompts were found to be more effective and contributive to more learning than recasts especially for low-level learners.

Philp (2003) investigated the effect of proficiency level and features of recast such as their 'length' and 'number of changes' on learners' noticing of recasts. 18 female and 15 male students participated in this study. They were from different proficiency levels. The participants were assigned to three groups (Low, Intermediate, and High) according to their performance in a placement session and the first treatment session. Then, they took part in five NS-NNS dyadic interaction sessions with three native speakers for more than two weeks. They also took part in test sessions during which they performed two tasks; a story-completion task similar to the one in the treatment sessions, and a spot-the-difference task in which the learners asked questions to find the differences between one picture and another almost identical one held by the NS. During the treatment sessions, Philp used some sets of pictures to elicit questions from the participants who performed two tasks; a picture-drawing task, in which learners asked questions about the picture held by their native partner and tried to draw a picture similar to it, and a story-completion task, during which a pictorial story was presented to the learners and they were to ask questions to discover the story behind the pictures. The NS provided recasts in response to the erroneous utterances, particularly question forms. The learners were to repeat the recast forms. The classroom interactions were recorded and transcribed for analysis. Recall was used as a measure of noticing, that is if learners could remember the provided recast, they were believed to have noticed the feedback. The results of analyses showed that there was a significant relationship between the proficiency level of learners and the recall of recasts. While high and intermediate groups recalled over $70 \%$ of the provided recasts, the low learners were able to recall $60 \%$ of the recasts. Overall, high and intermediate learners were more accurate on their recall of the recasts noticing recasts more than the low group. On the other hand, the results of a t-test for paired samples showed that shorter recasts were recalled with more accuracy than the long ones especially by high and intermediate learners. However, the low group recalled short recasts better than the long ones. Therefore, it can be concluded that the 
shorter recasts are noticed more easily and consistently irrespective of the learners' level of proficiency. As in Sheen's (2006) study, the number of changes proved to be an influential factor affecting the way learners perceive recasts. The fewer the number of changes, the better the participants could recall the recasts. Overall, recast length and the number of changes were determining factors in the way language learners were able to remember and notice the implicit feedback provided. Philp contends that learners are biased towards the feedback or recast they receive if it is beyond their current level of proficiency to understand it, meaning that if they are not developmentally ready for receiving feedback on a certain structure, then they roll back on their interlanguage to resolve it. Therefore, they analyze and interpret the recast in a way that suits their current level of proficiency and do not understand the gap between their interlanguage and the feedback provided to them in the form of recast. This result is consistent with the findings of Mackey and Philp (1998).

Mackey and Philp (1998) considered the role of proficiency on learners' noticing and implementation of recast. Investigating the role of recast on language acquisition, they compared the performance of groups of learners who received interactionally modified input with learners who received the same input containing intensive recasts in an attempt to investigate the effect of proficiency on learners' perception of recast, the effect of recasts on learners' short-term interlanguage development and the nature and content of learners' responses to recasts using a pretest, posttest, delayed posttest design. In contrast to other studies, Mackey and Philp considered the long-term effect of recasts on interlanguage development as opposed to short-term effects which have not been confirmed to exist according to the results of studies as previously mentioned (Lyster and Ranta, 1997; Panova and Lyster, 2002; Tsang, 2004). Thirty-five adult ESL learners were assigned to "readies" or "unreadies" groups based on their level of proficiency. Once assigned as "ready" or "unready", participants were randomly assigned to different groups: two interactor groups who performed three tasks (a picture drawing task, a story completion task, and a story sequencing task) in pairs with a NS interlocutor receiving no recasts; two recast groups who received intensive recasts of their non-target-like utterances from the native interlocutors as they performed the same tasks; and a control group that took the pre and post-tests only. The tasks were planned in a way to prepare the conditions for learners to produce question forms. The results show that the only group making significant progress was the 'Recast Ready' group, that is the group that was at a higher proficiency level than the 'Recast Unready' group receiving recast. In other words, the findings showed that sustained IL development took place only for the group that received recasts and was at a higher proficiency level than the other group receiving recasts. This provides further proof to the claim made at the beginning that recasts are especially effective for high-proficiency learners and that advanced learners have the knowledge and proficiency needed to resolve the ambiguity of recasts.

Mackey and Philp's study was conducted in a laboratory setting and the results of their study might not be generalizable to classroom contexts which are more natural. As Ellis, Loewen and Erlam (2006) note, "it is not easy to extrapolate the results obtained from laboratory studies that involve one-to-one interactions to classrooms in which the teacher interacts with the whole class" (p. 365). In fact, there might be distractions in a classroom that might not exist in a laboratory setting making recasts more salient in a laboratory setting and easier to notice. Ammar and Spada (2006) considered more specifically the effect of proficiency level on learners' perception and implementation of recasts in classroom contexts.

Ammar and Spada (2006) considered the effect of recasts and prompts (elicitation, repetition, and metalinguistic feedback that prompt self-correction) on learners with different proficiency levels. Clarification requests (a kind of prompt) were not included because, according to them, they are usually mistaken for feedback on meaning. They assigned ESL learners to three groups: one of the groups received feedback in the form of recasts, another in the form of prompts and there was also a control group. Learners took part in a four-week program during which they received instruction and feedback on third-person possessives, which according to Ammar and Spada was a difficult aspect of English grammar for the Francophone participants in this study. One pretest (before the treatment) and two posttests (one immediately after the treatment and one after 4 weeks from the end of the treatment) were administered to test the participants' knowledge of the target structure using written and oral tasks. The results of this study indicate that prompts were more effective than recasts for the low-proficiency learners. High-proficiency learners, on the other hand, effectively implemented both recasts and prompts to an equal extent. This further proves that learners with a high level of proficiency can resolve the potential ambiguity of recasts as against low-level learners who fail to perceive them to a desirable extent. Ammar and Spada pointed out two important factors as likely explanations for the superior effectiveness of prompts in comparison with recasts. According to them, explicitness or clarity of prompts and the opportunity for learners to self-repair seem to be the features that prepare the ground for a higher level of uptake for prompts. In fact, the teacher of the prompt group had been told to provide metalinguistic clues making the errors salient. He was also told to avoid explicit correction of the errors so that learners could correct them on their own.

As the results of the studies discussed above show, advanced learners notice recasts with more accuracy and implement the necessary changes to their utterance as required by the feedback. Besides, the most important reason mentioned as to the superiority of prompt was its saliency. Prompts were also more effective for low-proficiency learners. Furthermore, the low level of uptake for recast in Ellis et al (2006) and Fanselow's 
(1977) study might have been due to learners' low level of proficiency. Nevertheless, low-proficiency learners need some kind of assistance in order to notice the feedback provided in the form of recasts especially complicated recasts. This might be because they lack the competence needed to figure out the gap between their interlanguage and the input provided through recast on their own. Teachers should make them salient and easy to notice. As Sheen (2004) pointed out "the extent to which recasts lead to learner uptake and repair may be greater in contexts where the focus of the recasts is more salient" (p. 263).

The results of further studies (Lowen and Philp, 2006; Nassaji, 2007; Sheen, 2006; etc.) that investigated more specifically the characteristics of recasts contributing to effective learning confirm this claim showing that when recasts are made salient and more explicit, learners seem to have no difficulty noticing them and there is little difference in learners' uptake as a result of recast in comparison with prompt.

Sheen (2006) considered the effect of recast characteristics on learners' perception of recast. He conducted a comprehensive study in a classroom setting investigating the characteristics of recasts or different forms of recast trying to relate these characteristics to the uptake they result. The participants were twenty four 18 to 21 year-old ESL learners in New Zealand with two English native speaking teachers one having two years and the other five years of teaching experience, and ten 29 to 36-year-old EFL learners with two native speaking teachers, both having more than five years of experience in communicative language teaching. The participants were all at an intermediate level. The two data sets were combined because the purpose of the study, according to Sheen, was to investigate the characteristics of recasts and not to compare or contrast the two groups. The New Zealand ESL data were collected observing and audio-taping ten meaning-based English lessons and the Korea EFL data were taken from Sheen (2004), which was based on 12 hours of 13 English communicative lessons observed and recorded over a period of six weeks. Sheen identified all recast moves in the sequences of error treatment and classified them under two categories: Multi-move recasts and Single-move recasts. The multi-move recasts included corrective recasts (recasts that are preceded by repetition), repeated recasts ("the teacher repeats either fully or partially") and combination recasts (recasts combined with other types of feedback except explicit correction). In contrast to multi-move recasts, single-move recasts include only one recast move in a single turn. Sheen identified seven characteristics of single-move recasts taking insights from Lyster (1998a), Philp (2003) and some other studies. The first characteristic includes mode (declarative or interrogative). The second one concerns the 'scope' of recast which includes 'isolated' (during which the erroneous part is isolated and reformulated) and 'incorporated' recast which is followed by additional semantic content. The third category refers to 'reduction' according to which the teacher's corrective phrase can be either shorter than the erroneous utterance ('reduction) or just a repetition of the learner's wrong utterance ('non-reduction'). Length of the utterance is another factor referring to the length of the corrective recast. In this way, the corrective utterance might be classified as short, long or a clause involving at least two phrasal constituents. Number of changes also affects the way learners perceive corrective recasts. From this perspective, recasts may involve only one change or multiple changes. The sixth characteristic concerns the type of change depending on whether one adds or supplies a missing element (addition) or removes it (deletion). Learners might also be corrected on different linguistic areas or foci including pronunciation, vocabulary and grammar meaning that the type of error triggers the type of linguistic focus in the recast. Sheen calculated the frequencies of recast characteristics and the level of uptake following each recast movement. She examined the relationship between the different characteristics of recasts and the resulting uptake/repair. The results of analyses showed that single-move recasts were more dominant and frequent than multi-move recasts accounting for $79 \%$ of the recasts. Sheen also noted that repeated recasts were the most dominant among the multi-move recasts. The results of further analyses showed that declarative $(84 \%)$ and isolated recasts $(99 \%)$ and reduced/partial recasts $(66 \%)$ were much more prevalent. It was also found that recasts involving one change were more frequent accounting for $81 \%$ of the 233 recasts and these recasts were mostly in the form of substitution, which, according to Sheen, increased the saliency of recasts leading to a high level of uptake. The focus of recasts was more on grammatical mistakes. Recast on vocabulary was more common than recast on pronunciation. However, regarding the characteristics of recast that led to uptake, it was found that there was no significant relationship between single-move/multi-move recasts and learner uptake/repair. This might be due to the low counts of multi-move in comparison with single-move recasts. In fact, no firm conclusion can be drawn due to the low rate of occurrence for multi-move recasts. Nonetheless, corrective recasts and combination recasts led to the highest (100\%) level of successful repair. Overall, a number of recast characteristics were found to be related to high level of uptake: pronunciation focus, shortness, and substitution. As Sheen notes, this finding in consistent with the findings of Lyster and Ranta (1997) and Mackey et al.'s (2000) study concluding that recast on phonological and lexical rather than morphosyntactic errors is more beneficial and much more likely to lead to uptake. Regarding the shortness of recast and its relationship with higher levels of uptake, as Sheen (2006) also notes, Philp (2003) came to the same conclusion believing that long recasts are difficult to keep in the working memory and therefore less likely to be noticed and implemented in the way of correction. Finally, Sheen notes that interrogative recasts did not produce a high level of repair citing Lyster (1998b) that "interrogative recasts often serve as conformation checks" (P. 386). She attributes the successful repair following substitution (type of change) and correction of pronunciation errors (linguistic focus) 
to the 'length' and 'number of changes' stating that "uptake and subsequent repair are more likely when the linguistic focus of recasts is on pronunciation and when the type of change involved substitution because these characteristics are linked with length (word or short phrase) and a single change" (P. 386).

The results of Sheen's (2006) study are almost consistent with Loewen and Philp's (2006) study. Loewen and Philp also came to the conclusion that "stress, declarative intonation, one change, and multiple feedback moves were predictive of successful uptake." They found out that "interrogative intonation, shortened length, and one change were predictive of the accuracy of the test scores" (p. 1).

As it can be noted, while Sheen (2006) came to the conclusion that interrogative recasts were of no benefit to repair, Loewen and Philp (2006) found out that interrogative recasts do have an effect on the development of learners' accuracy. This inconsistency is the result of the nature of recasts in the two studies. That is, Sheen distinguished between implicit (incorporated, interrogative and grammar-focused) and explicit (reduced, short, and single-error-focused) recasts regarding interrogative recast as implicit. Loewen and Philp also noted that "an interrogative recast is ambiguous as corrective feedback because the learner may interpret it either as corrective or as a request to confirm the intended meaning" (p. 540). But the interrogative recasts in their study is salient as against the recasts in Sheen's study because they are short and involve only one change leading to more accuracy of production. In this way, interrogative recast is made more salient helping language learners recognize it as corrective feedback rather than confirmation check, one of the functions of interrogative recast as Lyster (1998b) pointed out.

Panova and Lyster (2002) also observed that recasts that reduce the learner's utterance and add stress to emphasize the corrective modification are more effective at eliciting repetition of the recast and are more likely to be identified by learners as corrective feedback. Doughty and Varela (1998) further distinguished between recast and corrective recast in that the latter is more explicit than the former. Corrective recast, they said, is a two-step procedure: 1) repetition (usually with rising intonation) to draw attention followed by 2) recast to provide, contrastively, the necessary target exemplar. In this way, the teacher or provider of feedback makes the recast more salient and easier to notice. This is a useful strategy to make recast noticeable especially for learners with a low language abilities. Accordingly, the low uptake in observational studies (Fanselow, 1977; Ellis et al., 2006; Lyster and Ranta, 1997; Panova and Lyster, 1998; etc.) is attributable to the non-saliency of recasts and the low proficiency of the learners and their inability to reconcile the ambiguity and find the gap in their interlanguage.

In a more comprehensive study, Nassaji (2007) distinguished between isolated recasts and embedded recasts, while Lyster (1998b) referred to the both as isolated recasts. In isolated recast, according to Nassaji, the teacher repeats the erroneous part of the learners' utterance while in embedded recasts the whole utterance is repeated. The main purpose of the study was to investigate the relationship between elicitation and reformulation (recast) as two major types of interactional feedback on learner repair. He also emphasized the role of saliency and explicitness in making feedback efficient and effective. Nassaji went further delineating the subtypes of the two types of feedback under investigation. According to him, the subtypes of recast include Isolated recast - prompt, recast + prompt, Embedded recast - prompt, Embedded recast + prompt, Recast + enhanced prompts ("with a rising intonation and/or added stress as well as with other additional verbal prompts") and Recast + expansion (adding new information to it). Elicitations, on the other hand, included five subtypes: Unmarked elicitation (without marking the error), marked elicitation (referring to the error by interrogative repetition), Marked elicitation + prompt, Marked elicitation + enhanced prompt and finally Elliptical elicitation which involves "repeating the utterance up to the error and waiting for the learner to supply the correct form" (p.529). 42 adult ESL learners engaged in picture-description tasks paired and interacting with two native-speaker English language teachers who provided feedback on the learners' erroneous utterances. In fact, the teachers had been instructed on and become familiar with different forms of recast and elicitation as illustrated in this study. The results showed that, surprisingly $91 \%$ of the participants' utterances were erroneous. Among the types of feedback, reformulation or recast was the most dominant accounting for $45.5 \%$ of the provided feedback. Only $27.5 \%$ percent of the erroneous utterances were followed by elicitations and $27.1 \%$ percent by other types of feedback. Of all the provided recasts, only $34 \%$ led to successful repair, $5 \%$ led to partial repair and $61 \%$ led to no repair at all. Elicitations led to a slightly more repair (31\% successful repair and $10 \%$ partial repair) though recasts resulted in more successful repair. Nassaji analyzed the relationship between different subtypes of recast and elicitation and tried to find the relationship between features or different types of feedback and repair. According to the findings, isolated recast - prompt and recast + expansion led to no repair. On the other hand, isolated recast + prompt led to $64 \%$ repair. Furthermore, embedded recasts +prompt led to more repair than recasts -prompt and recast +enhanced prompt led to $62 \%$ repair. "Overall, among reformulations, isolated recast + prompt and recasts + enhanced prompt led to the highest degree of repair" (p. 533). The results were in fact an indication of the need to make feedback and recast, specifically, more salient and easy to notice. On the other hand, among elicitations, marked elicitations + enhanced prompt and elliptical elicitations led to the highest level of successful repair. On the whole, the results showed that when feedback is followed by a kind of feedback enhancement prompt, it becomes more efficient and leads to more repair. In other words, the prompts make 
feedback more salient and easy to notice. As Nassaji notes, "When interactional feedback is combined with emphasis or additional prompts, it might give the feedback more attentional focus and hence might make the learner more likely to notice the corrective purpose of the feedback" (p. 537) whether in the form of recast or elicitation.

In addition to proficiency level and characteristics of recasts, some researchers (e.g., Trofimovich et al., 2007) considered the effect of personal characteristics on learners' perception of recast. In a laboratory-based study, Trofimovich et al. (2007) investigated the effect of proficiency level and the effect of personal characteristics on noticeability of recasts. These characteristics included four cognitive processing factors such as phonological memory, working memory, attention control and analytical ability. The first of these factors, i.e. working memory, "underlies an individual's ability to simultaneously process and store verbal information relevant to the processing task at hand" (p. 173). During the interaction between the learners, working memory determines the level of verbal information learners can attend to. It means that the higher the working memory is the more information one can process and the more one may be able to attend to the recasts provided during the interaction. Therefore, higher level of working memory may lead to a higher level of perception of recasts. The second factor, that is phonological memory, refers to "an individual's capacity to retain spoken sequences temporarily in a short-term memory store" (p. 174). In this way, the higher levels of phonological memory will increase the possibility of noticing recasts by the learners after they have been provided. Analytical ability, on the other hand, includes "an individual's sensitivity to grammatical structure" meaning that the more analytical ability one has the more he or she is likely to pay attention to the structure of the utterances provided in the form of recasts. The final factor investigated in this study was attention control or "the ability to efficiently allocate attention among different aspects of language or different cognitive processing tasks" (p. 174). Attention control or attention span might be influenced by learners' age. Adult learners are believed to have higher attention span than children and adolescents being able to focus on the input provided to them in the form of recasts. Taking this argument into account, adults are more likely to notice recasts than younger learners. However, Trofimovich et al. (2007) did not consider the effect of age on learners' perception of recasts. The participants performed an online picture description task which elicited a particular feature of the L2 on which they received recasts when using erroneous forms while describing the pictures. After hearing the recast, they indicated whether they noticed the gap between their utterance and the feedback provided. Then they were asked to describe the utterance again. A non-word recognition task was used to measure learners' phonological memory. In fact, the learners judged whether two consecutively presented sequences of pronounceable English non-words were in the same or in a different order. The Letter-Number Sequencing subtest from the Wechsler Adult Intelligence Scale was also used to assess the participants' working memory. Learners were required to manipulate information online. In this way, they measured how learners process and execute the information using their working memory. The Trail Making Test was also used to estimate attention control. Finally, part IV of the Modern Language Aptitude Test was used to assess the participants' Analytical ability.

The study showed that, overall, learners benefited from the recasts provided. They were more likely to notice feedback (recast) on lexical rather than morphosyntactic errors. The findings of Mackey et al. (2000) also showed that learners had difficulty noticing and using feedback on morphosyntactic errors. Recasts targeting lexical errors led to higher noticing rates than recasts aimed at morphosyntactic errors. Furthermore, the positive effect of proficiency level was also confirmed in this study by the fact that higher proficiency learners benefited from recast more than the lower proficiency learners. As Trofimovich et al. also note, the state of their 'readiness' to acquire a form enhances the usefulness of recasts for them. However, learners with higher phonological memory, efficient attention control and strong analytical ability seemed to have less difficulty in the perception of feedback on morphosyntactic errors. According to Trofimovich et al., each of the factors seemed to have an independent effect on learners' noticing of recasts and improvement using the feedback provided in the form of recast. Phonological memory, for example, "ensured that learners maintain their own spoken utterances and those produced by others, thereby making these utterances available for subsequent storage or processing" (p. 193). On the other hand, learners with a high analytical ability seem to be more likely to engage in a deeper understanding and processing of feedback (recast). In fact, analytical ability and phonological memory seem to have a delayed effect on learners' performance. This can be good evidence against Truscott and Hsu's (2008) claim that the effect of corrective feedback diminishes in the long run.

\section{Conclusion}

The effect of recast on learners' interlanguage development has been questioned by some researchers (Sheen, 2004; Truscott, 1996). In fact, the results of many studies (Fanselow, 1977; Lyster and Ranta, 1997; Panova and Lyster, 1998; Sheen, 2004; etc.) show that although most of the feedback is provided in the form of recast, it is the elicititative types of feedback (metalinguistic, elicitation, prompt, etc.) that lead to an acceptable level of improvement. This has shed doubt on the effectiveness of recasts. However, in these studies, most of which are observational, the factors that led to the inefficacy of recast were not specifically investigated. In fact, no distinction was made between recast on meaning and recast on form. There is a need for studies that investigate the specific features of recasts, as Ellis and Sheen (2006) also noted. The results of further studies (Ammar and 
Spada, 2006; Lyster, 1998b; Philp, 2003; Sheen, 2006; etc.) investigating the features of recast and the factors affecting its effectiveness elucidated the factors that make recasts effective or non-efficient. Although these studies suffer from some methodological problems such as lack of a homogeneous construct and different correction practices as required by different contexts, as noted by Ellis and Sheen (2006), these problems do not seem to have affected learning. Surprisingly, researchers have come up with quite similar results. The results of these studies confirmed the effect of two very important factors on learners' perception of recast: learners' level of proficiency or developmental readiness and linguistic features of recasts.

In contrast to Ellis and Sheen's (2006) claim that it is difficult to distinguish between implicit and explicit recasts, explicit or didactic recasts, as mentioned in the studies that investigated the effect of different features of recast, were shown to be distinguishable by certain signals and factors such as shortness, stress, the focus of recasts, etc.

The results of some other studies (Lyster and Ranta, 1998b; Mackey et al., 2000; Trofimovich et al., 2007) confirmed the effect of another important factor, that is the component aimed by the recast. In other words, recasts on phonological and lexical rather than morphosyntactic errors were found to be more beneficial and much more likely to lead to uptake. Furthermore, researchers have started investigating the effect of some other factors on learners' perception of recast. Trofimovich et al. (2007), for example, considered the effect of cognitive characteristics such as working memory, phonological memory, attention control and analytical ability on learners' perception of recast.

Overall, instead of arguing against the use of recast as an unobtrusive type of feedback and especially useful during oral interactive activities, it seems that there is a special need for further studies to investigate the facilitative factors, e.g. the effect of features of recast and personal and cognitive characteristics that affect the level of uptake as a result of recast. Lyster and Izquierdo (2009) came to the conclusion that recasts can be as effective as prompts if learners are exposed to more and more positive exemplars and "have the opportunity to infer negative evidence" (p. 453-454). Ellis and Sheen (2006) also pointed out the need for specific studies to investigate facilitative or disruptive processes affecting the usefulness of recast. In fact, there might be many other factors which make recast more effective or non-efficient. For instance, the effect of age can be an influential factor worth investigation. As noted in Brown (2000), adult and adolescent learners have a higher level of attention span and control that was shown to have a positive effect on learners' noticing of recasts in Trofimovich et al.'s (2007) study. Further studies are needed to investigate the factors that lead to the effectiveness of recast on phonological and lexical errors rather than morphosyntactic. There is also a need for further studies to shed light on the relationship between personal characteristics and uptake for recast or other types of feedback.

\section{References}

Ammar, A. (2008). Prompts and recasts: Differential effects on second language morphosyntax. Language

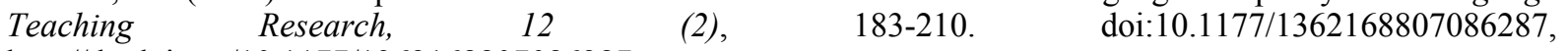
http://dx.doi.org/10.1177/1362168807086287

Ammar, A., and N. Spada. (2006). One size fits all? Recasts, prompts, and L2 learning. Studies in Second Language Acquisition. 28, 543-74. doi:10.1017/S0272263106060268, http://dx.doi.org/10.1017/S0272263106060268

Brown, H. D. (2000). Principles of language learning and teaching. New York: Pearson Education.

Corder, S. P. (1981). Error analysis and interlanguage. Oxford: Oxford University Press.

Doughty, C. (2001). Cognitive underpinning of focus on form. In P. Robinson (Ed.), Cognition and second language instruction (pp. 206-257). New York: Cambridge University Press.

Doughty, C., and Varela, E. (1998). Communicative focus on form. In C. Doughty and J. Williams (Eds.), Focus on form in classroom second language acquisition (pp. 114-138). Cambridge: Cambridge University Press.

Ellis, R., Loewen, S. and Erlam, R. (2006). Implicit and explicit corrective feedback and the acquisition of L2 grammar. Studies in Second Language Acquisition, 28 (2), 339-368. doi:10.1017/S0272263106060141, http://dx.doi.org/10.1017/S0272263106060141

Ellis, R., and Sheen, Y. (2006). Reexamining the role of recasts in second language acquisition. Studies in Second Language Acquisition, 28 (4), 575-600. doi:10.1017/S027226310606027X, http://dx.doi.org/10.1017/S027226310606027X

Fanselow, J. F. (1977). The treatment of error in oral work. Foreign Language Annals, 10, 583-593. doi:10.1111/j.1944-9720.1977.tb03035.x, http://dx.doi.org/10.1111/j.1944-9720.1977.tb03035.x

Gass, S. (2003). Input and interaction. In C. J. Doughty and M. H. Long (Eds.), The handbook of second language acquisition (pp. 224-255). Malden, MA: Blackwell.

Han, Z. (2002). A study of the impact of recasts on tense consistency in L2 output. TESOL Quarterly, 36, 543-572. doi:10.2307/3588240, http://dx.doi.org/10.2307/3588240 
Leeman, J. (2003). Recasts and second language development: Beyond negative evidence. Studies in Second Language Acquisition, 25, 37-63.

Loewen, S. and Philp, J. (2006). Recasts in the adult L2 classroom: characteristics, explicitness and effectiveness. Modern Language Journal, 90 (4), 536-556. doi:10.1111/j.1540-4781.2006.00465.x, http://dx.doi.org/10.1111/j.1540-4781.2006.00465.x

Long, M. (1996). The role of the linguistic environment in second language acquisition. In W. Ritchie and T. Bhatia (Eds.), Handbook of second language acquisition (pp. 413-468). San Diego: Academic Press.

Lyster, R. (1998a). Form in immersion classroom discourse: In or out of focus? Canadian Journal of Applied Linguistics/Revue Canadienne De Linguistique Appliquee, 1 (1-2), 53-82.

Lyster, R. (1998b). Negotiation of form, recasts, and explicit correction in relation to error types and learner repair in immersion classrooms. Language Learning, 48 (2), 183-218. doi:10.1111/1467-9922.00039, http://dx.doi.org/10.1111/1467-9922.00039

Lyster, R. and Izquierdo, J. (2009). Prompts Versus Recasts in Dyadic Interaction. Language Learning, 59 (2), 453-498. doi:10.1111/j.1467-9922.2009.00512.x, http://dx.doi.org/10.1111/j.1467-9922.2009.00512.x

Lyster, R., and Ranta, L. (1997). Corrective feedback and learner uptake: Negotiation of form in communicative classrooms. Studies in Second Language acquisition, 26 (3), 399-432.

Mackey, A., Gass, S., and McDonough, K. (2000). How do learners perceive interactional feedback? Studies in Second Language Acquisition, 22, 471-497. doi:10.1017/S0272263100004022, http://dx.doi.org/10.1017/S0272263100004022

Mackey, A. and Philp, J. (1998). Conversational interaction and second language development: Recasts, responses, and red herrings? Modern Language Journal, 82, 338-356. doi:10.2307/329960, http://dx.doi.org/10.2307/329960

Nassaji, H. (2007). Elicitation and reformulation and their relationship with learner repair in dyadic interaction. Language Learning, 57, 511-548. doi:10.1111/j.1467-9922.2007.00427.x, http://dx.doi.org/10.1111/j.1467-9922.2007.00427.x

Nassaji, H. (2009). Effects of recasts and elicitations in dyadic interaction and the role of explicitness. Language Learning, 59, 411-452. doi:10.1111/j.1467-9922.2009.00511.x, http://dx.doi.org/10.1111/j.1467-9922.2009.00511.x

Nicholas, H., Lightbown, P., \& Spada, N. (2001). Recasts as feedback to language learners. Language Learning, 51, 719-758. doi:10.1111/0023-8333.00172, http://dx.doi.org/10.1111/0023-8333.00172

Oliver, R. (1995). Negative feedback in child NS-NNS conversation. Studies in Second Language Acquisition, 17, 459-481. doi:10.1017/S0272263100014418, http://dx.doi.org/10.1017/S0272263100014418

Panova, I. and Lyster, R. (2002). Patterns of corrective feedback and uptake in an adult ESL classroom. TESOL Quarterly, 36, 573-95. doi:10.2307/3588241, http://dx.doi.org/10.2307/3588241

Philp, J. (2003). Constraints on "noticing the gap": Nonnative speakers' noticing of recasts in NS-NNS interaction. Studies in Second Language Acquisition, 25, 99-126.

Sheen, Y. (2004). Corrective feedback and learner uptake in communicative classrooms across instructional settings. Language Teaching Research, 8 (3), 263-300. doi:10.1191/1362168804lr146oa, http://dx.doi.org/10.1191/1362168804lr146oa

Sheen, Y. (2006). Exploring the relationship between characteristics of recasts and learner uptake. Language Teaching Research, 1, $361 \quad-392$ doi:10.1191/13621688061r203oa, http://dx.doi.org/10.1191/13621688061r203oa

Trofimovich, P., Ammar, A., and Gatbonton, E. (2007). How effective are recasts? The role of attention, memory, and analytical ability. In A. Mackey (Ed.), Conversational interaction in second language acquisition (pp.144-171). Oxford: Oxford University Press.

Truscott, J. (1996). The case against grammar correction in L2 writing classes. Language Learning, 46, 327-369. doi:10.1111/j.1467-1770.1996.tb01238.x, http://dx.doi.org/10.1111/j.1467-1770.1996.tb01238.x

Truscott, J. (1999). What's wrong with oral grammar correction. Canadian Modern Language Review, 55, 437-456. doi:10.3138/cmlr.55.4.437, http://dx.doi.org/10.3138/cmlr.55.4.437

Truscott, J., and Hsu, A. Y. (2008). Error correction, revision, and learning. Journal of Second Language Writing, 17, 292-305. doi:10.1016/j.jslw.2008.05.003, http://dx.doi.org/10.1016/j.jslw.2008.05.003

Tsang, W. (2004). Feedback and uptake in teacher-student interaction: An analysis of 18 English lessons in Hong Kong secondary classrooms. Regional Language Centre Journal, 35 (2), 187-209. 